http://jmscr.igmpublication.org/home/

ISSN (e)-2347-176x ISSN (p) 2455-0450

crossref DOI: https://dx.doi.org/10.18535/jmscr/v8i7.58

\title{
A Rare Presentation of Epidermal Mucinosis \& Penile Inraepithelial Neoplasia
}

\author{
Authors \\ Meghadipa Mandal ${ }^{1}$, Tushar Kanti Das ${ }^{2}$ \\ ${ }^{1}$ Post Graduate trainee, Department of Pathology, R. G Kar Medical College \& Hospital, Kolkata-700102, \\ West Bengal India \\ ${ }^{2}$ Department of Pathology, R. G. Kar Medical College \& Hospital, Kolkata-700004, West Bengal India \\ Corresponding Author \\ Meghadipa Mandal
}

Abstract
Cutaneous mucinosis is a lesser explored area of dermatopathology. There is not much literature
regarding cases that show the association between cutaneous mucinosis and Penile Intraepithelial
neoplasia (PeIN). This case presents such rare association in a 50 years old male patient.
Keywords: Cutaneous Mucinosis, Penile Intraepithelial Neoplasia, 50 years old, Male.

\section{Introduction}

Penile Intraepithelial Neoplasia (PeIN) is carcinoma in situ of penis, most commonly in glans penis of uncircumscribed males. Etiology is multifactorial, ranging from chronic irritation, poor hygiene to genital herpes simplex \& HPV infection. The histomorphology is similar to those of carcinoma in situ, as in Bowen's disease.

Mucins are high molecular weight $\mathrm{O}-\& \mathrm{~N}$-linked glycoproteins, whose role in cutaneous pathologies has remained largely obscured. The normal skin exhibits restricted expression of mucins. Mucins are over expressed in various benign \& malignant skin disorders ${ }^{1}$.Mucins may also be expressed in pre-malignant lesions like Epidermolysis bullosa \& Bowen's disease ${ }^{2}$. Much is not known about association between mucins \& penile neoplasms, except for a case series of six clear cell carcinomas of the penile foreskin, showing intense positivity with anti-MUC1 antibody ${ }^{3}$. Epidermal Mucinosis is a well-known entity associated with plaque stage of Mycosis Fungoides.

This case report demonstrates a very rare presentation of Epidermal Mucinosis in the background of Penile Intraepithelial Neoplasia (PeIN), in a 50 years old male patient.

\section{Clinical Presentation}

A 50 years old male patient presented in dermatology OPD with complaints of a slowly expanding, painless, non-itchy whitish patch on foreskin of an uncircumscribed penis. Patient was subjected to biopsy of foreskin \& the sample was sent to the department of Pathology for histopathological examination. 


\section{Grossing}

A $1.5 \mathrm{~cm}$ long skin-covered tissue strip was received, with superficial whitish patch. The entire tissue was submitted for processing.

\section{Histopatological Study}

Sections from the strip of tissue showed epidermis \& dermis. Epidermis showed widespread acanthosis, papillomatosis with mild dermoepidermal junction inflammation. There were areas of spongiosis \& dysplasia. There were prominent, wide areas of mucinous material, which was further confirmed by PAS/ Alcian blue stain. However, there was no epidermotrophism or Pautrier micro abscess. No areas of invasive carcinoma were demonstrated in any of the sections examined. There was no prominent koilocytic atypia demonstrated in any of the sections. The above histomorphological picture suggested the diagnosis of Epidermal Mucinosis in the background of Penile Intra-epithelial neoplasia.

\section{Discussion}

Penile intra-epithelial neoplasia (PeIN) normally presents as erythematous, velvety, shiny plaque in glans or prepuce of elderly individual. Epidermal Mucinosis on the other hand is mostly seen to be associated with Mycosis Fungoides. There is no known literature that explores the association between these two entities. This posed the main diagnostic challenge in this case.

Our case presented in Dermatology OPD, with a whitish plaque, contrary to reddish plaque in PeIN. After examination of $\mathrm{H} \& \mathrm{E}$ sections, the histomorphology showed features of Mild PeIN (Figure 1) along with mucin-filled areas in epidermis (Figure 2) with mild dermo-epidermal chronic inflammatory infiltrate (Figure 3 ).

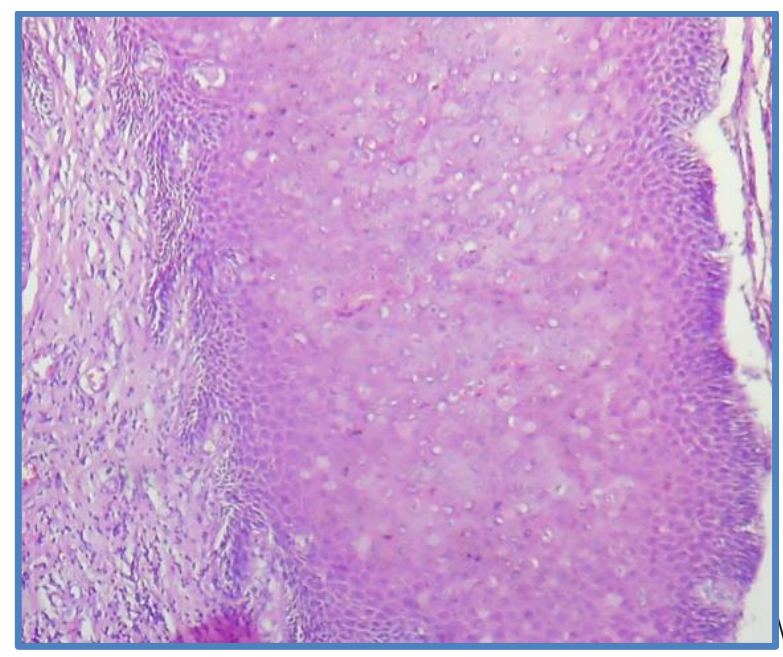

Fig. 1 Area of Penile Intra-Epithelial Neoplasia (PeIN)

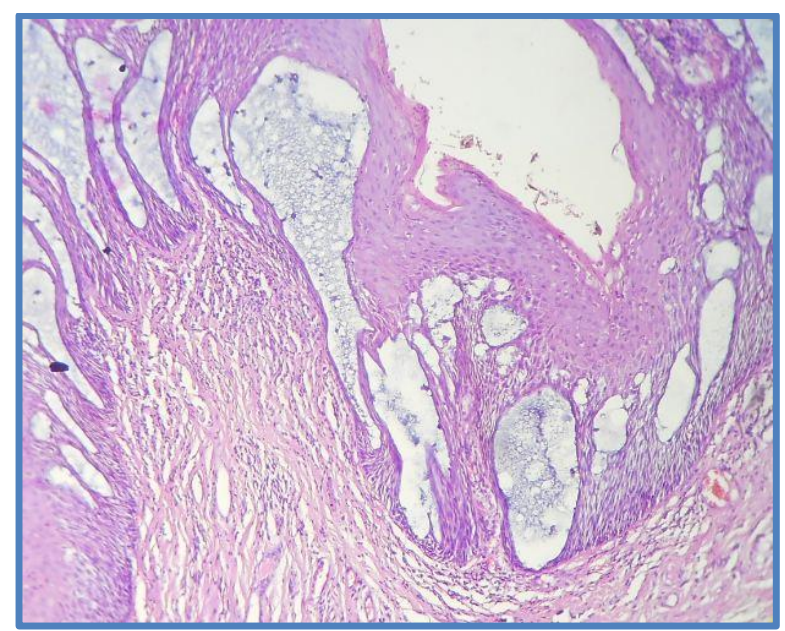

Fig. 2 Extensive areas of Epidermal Mucinosis

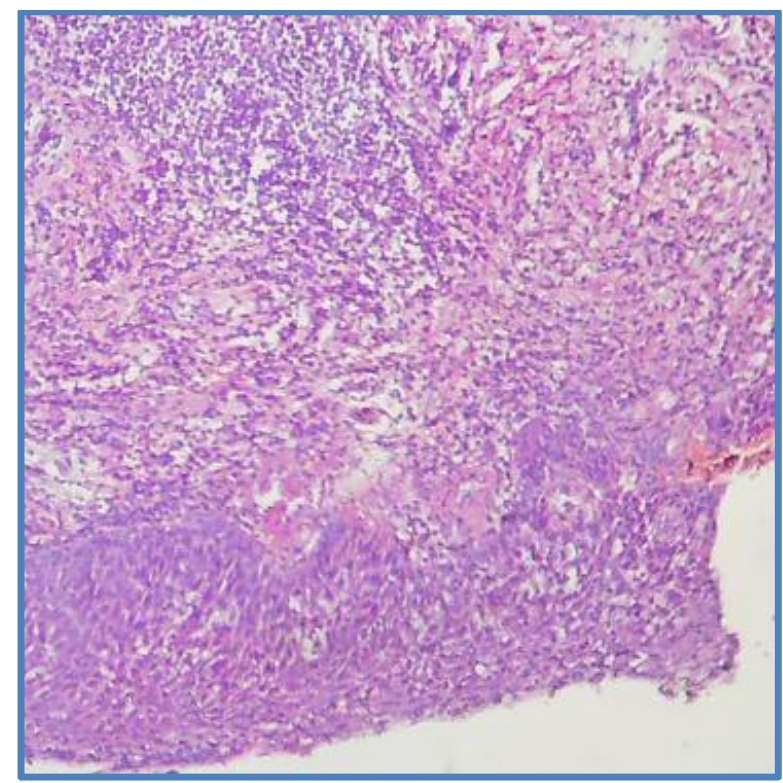

Figure 3 Areas of dermo-epidermal inflammation $\&$ mild PeIN. 


\section{JMSCR Vol||08||Issue||07||Page 367-369||July}

There were extensive areas of acanthosis, papillomatosis, parakeratosis \& spongiosis (Figure $4,5)$.

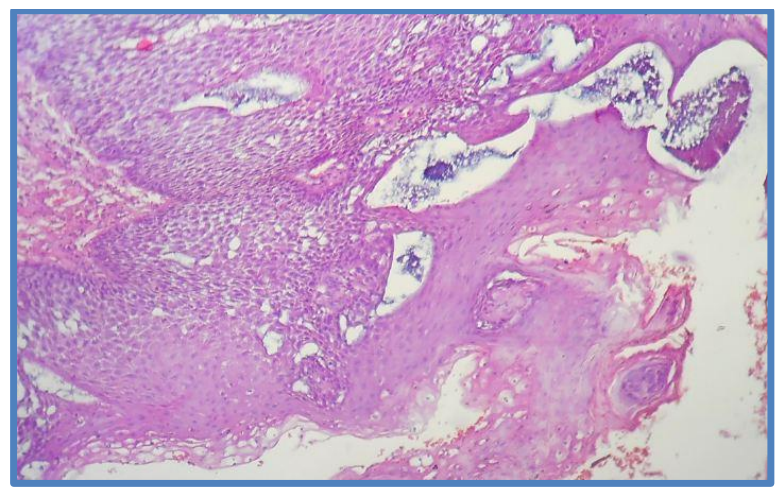

Fig. 4 Areas of acanthosis, papillomatosis, parakeratosis \& epidermal mucinosis.

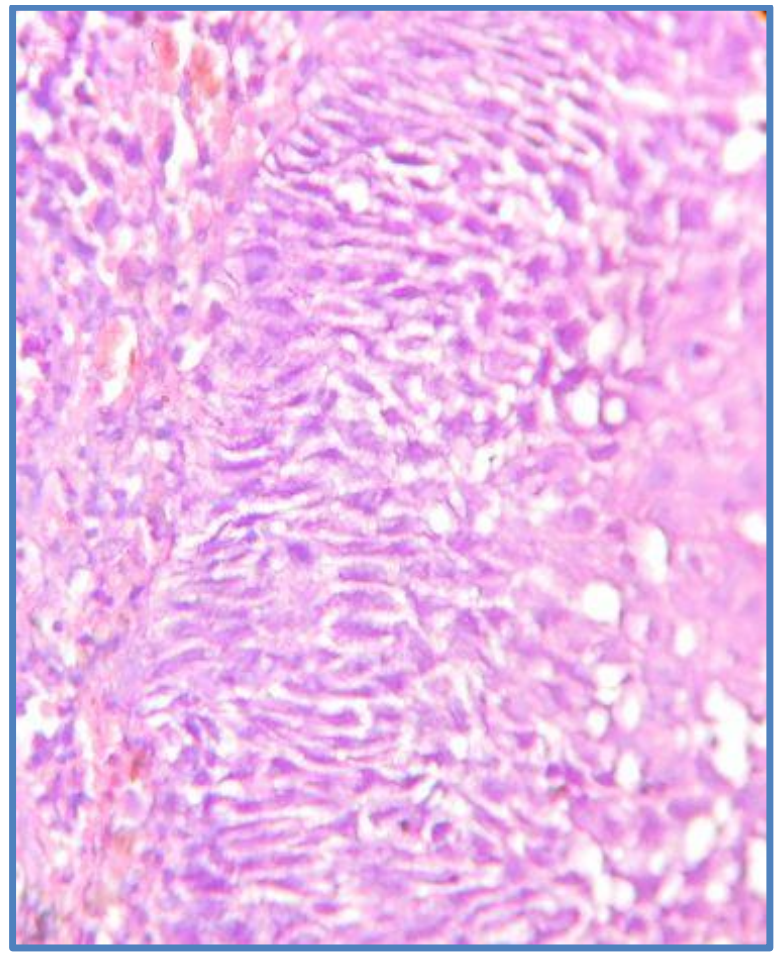

Fig. 5 Areas of spongiosis

After extensive research, no previous case reports were found to have this dual picture. Whether there is any role of mucin in progression from insitu to invasive carcinoma is also not clear due to paucity of cases with this rare association. Mucin in epidermis was further confirmed by PAS/ Alcian blue stain (Figure 6).

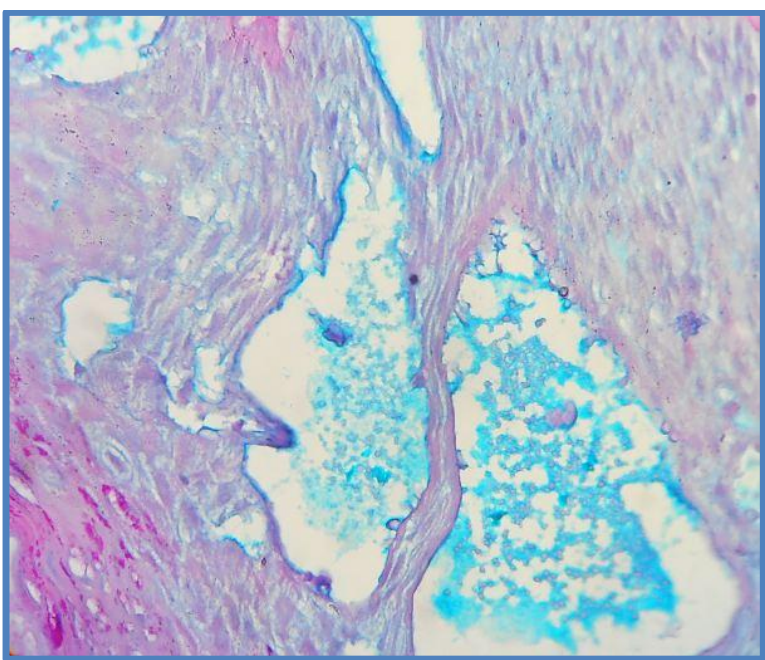

Fig. 6 Epidermal Mucinosis demonstrated by PAS/ Alcian Blue stain.

Hence, the final histomorphological diagnosis was made.

\section{Conclusion}

Cutaneous Mucinosis is a less explored area in dermatology. The exact mechanism that associates these two separate entities needs to be explored.

\section{References}

1. Chakraborty S., et al. Role of Mucins in the Skin during Benign and Malignant Conditions. Cancer Lett. 2011; 301(2): 127-141.

2. Cooper TW, Bauer EA. Epidermolysis bullosa: a review. Pediatr. Dermatol. 1984; 1:181-188.

3. Liegl B, Regauer S. Penile clear cell carcinoma: a report of 5 cases of a distinct entity. Am. J. Surg. Pathol. 2004; 28:1513-1517. 